\title{
AS MULHERES JOVENS NA LUTA PELA CIDADE: UMA ANÁLISE DE OCUPAÇÕES SECUNDARISTAS
}

\author{
YOUNG WOMEN IN THE FIGHT FOR THE CITY: AN ANALYSIS OF HIGH SCHOOL OCCUPATIONS
}

\section{RESUMO}

A teoria tradicional sobre o direito à cidade resultou em uma ausência de debate sobre mulheres e gênero quanto ao uso e pertença ao espaço urbano, apagando as diferentes formas de vivenciar a cidade entre homens e mulheres. A partir dessa lacuna debatemos o direito à cidade numa perspectiva feminista e interseccional, argumentando sobre as diferentes experiências de mulheres nos espaços urbanos a partir de raça, classe e geração. Depois, pensando em atos públicos do movimento feminista, como a Marcha das Vadias, discutimos os diferentes posicionamentos e formas de ação política dentro do feminismo a partir de marcadores sociais de diferença, tomando como ponto central a questão geracional. Com isso nos perguntamos: como as mulheres jovens lutam nas e pelas cidades? Para responder essa questão fazemos uma análise das entrevistas com mulheres jovens que participaram do movimento de ocupações secundaristas de 2015 e 2016, discutindo seu protagonismo no movimento, além de outras questões como os processos de subjetivação desencadeados na luta pelas cidades.

Palavras-chave: Direito à cidade. Feminismo. Mulheres jovens. Ocupações secundaristas.

\begin{abstract}
The traditional theory about the right to the city resulted an absence of debate about women and gender in the use and belonging to cities, erasing the different ways of experiencing the city between men and women. From this blank, we debated the right to the city in a feminist and intersectional perspective, arguing about the different experiences of women in urban spaces from race, class and generation. Then, thinking about public acts of the feminist movement, such as the March of Sluts, we discussed the different positions and forms of political action within feminism based on social markers of difference, taking the generational issue as a central point. Thus we ask ourselves how do young women fight in and for cities? To

\footnotetext{
Hugo Oliveira

Mestrando no Programa de Pós-Graduação em Sociologia da Universidade Federal de Goiás. E-mail: hugodeoliveirao3@gmail.com

Lorena de Oliveira

Mestranda no Programa de Pós-Graduação Interdisciplinar em Direitos Humanos da Universidade Federal de Goiás. E-mail: oliveiralorena@discente.ufg.br

Eliane Gonçalves

Pós-Doutora em Ciências Sociais. Professora de Sociologia na Faculdade de Ciências Sociais da Universidade Federal de Goiás. E-mail: elianego.lilica@gmail.com
} 
answer this question, we analyze interviews with young women who participated in the secondary and secondary occupation movement in 2015 and 2016, discussing their role in the movement, in addition to other issues such as subjectivation processes triggered in the struggle for cities.

Key words: Right to the city. Feminism. Young women. High school occupations.

\section{Introdução}

Para a socióloga Saskia Sassen, a questão da busca por uma vida melhor é central nos movimentos de migrações/expulsões, nos movimentos sociais após Segunda Guerra Mundial e também nas lutas pelas cidades e pelos espaços urbanos. Por isso, a vida nas cidades sempre esteve envolta por relações conflituosas devido à distribuição desigual de recursos necessários à produção da vida, colocando a seguinte questão: “Cidades para todos ou para quem tem poder?”. Nessa perspectiva, podemos pensar como as cidades também foram configuradas por relações de poder baseadas em gênero, construindo diferentes experiências sociais para homens e mulheres.

No entanto, a teoria tradicional sobre o direito à cidade tem se dedicado ao direito coletivo de dar forma ao processo de urbanização, focalizando grupos sociais excluídos pelos processos de industrialização, globalização e gentrificação, sem questionar a importância do gênero nos processos de urbanização e acesso à cidade. Na primeira seção deste artigo procuramos dar respostas a esta ausência pensando o uso e a pertença ao espaço urbano numa perspectiva feminista e de gênero. Ainda assim, pensar apenas o gênero não seria suficiente, uma vez que outros marcadores de diferença afetam a experiência nas cidades, por isso o faremos a partir de uma perspectiva interseccional, discutindo como raça, classe e geração se combinam com essa categoria na produção da vida das mulheres nas cidades.

Essas diferentes experiências também se traduzem em diferentes perspectivas e formas de ação política no movimento feminista, que podem ser observadas a partir de atos públicos realizados nas cidades. Dessa forma, na segunda seção, analisamos essas diferenças a partir da questão do uso do corpo e da nudez na Marcha das Vadias. Essa discussão é fundamental, pois insere a diferença geracional no feminismo, o que nos leva ao sujeito principal dessa pesquisa, as mulheres jovens. Para nós, as mulheres jovens e as jovens feministas são uma das principais forças materializadoras da luta feminista nas cidades, o que nos leva a uma pergunta: como as mulheres jovens lutam nas e pelas cidades?

Dentre as inúmeras possibilidades de resposta, destacamos a experiência de jovens estudantes no movimento de ocupações secundaristas de 2015 e 2016. A partir do conjunto das entrevistas realizadas com estudantes que participaram dessas mobilizações, apresentamos, neste artigo, três delas, destacando seus protagonismos no contexto maior de processos de subjetivação gerados na luta pelas cidades, 
a capilaridade do feminismo em outros movimentos e a dimensão formativa das ocupações. Por fim, concluímos que a luta das mulheres jovens pela cidade fornece uma experiência crítica desses espaços por meio de uma intervenção política, que coloca a importância das categorias gênero e geração na compreensão das relações de poder nas cidades.

\section{Gênero e cidade: uso e pertença ao espaço urbano numa perspectiva interseccional}

As cidades e suas variadas formas de organização tornaram-se um amplo objeto de estudo em diferentes áreas de conhecimento. Diversas autoras e autores se dedicaram ao tema e desenvolveram importantes conceitos, destacando-se, entre eles, o de direito à cidade, definido por David Harvey como: "o direito de mudar a nós mesmos pela mudança da cidade" (HARVEY, 2012, p. 74). No entanto, os estudos tradicionais sobre o tema não abordaram a questão de gênero em suas análises. Com isso, percebe-se que ao se falar em direito à cidade não está explícita a ideia de que se trata também de uma pauta feminista, já que as perspectivas de gênero não foram originariamente englobadas. Por isto, é necessário relacionar de que modo o direito à cidade e as formas de ocupação urbana se relacionam diretamente com as pautas feministas interseccionais e também com o sentimento de pertença das mulheres no espaço urbano, o que demonstraremos nesta seção.

Dito isto, destacamos que uma teorização mais recente sobre o direito à cidade evidencia que incluir a perspectiva de gênero na análise da ocupação dos espaços urbanos é essencial. Essa mudança teórica está fundamentada, dentre outros fatores, pelo fato de a vivência na cidade acarretar diferentes experiências para homens e mulheres, as quais são decorrentes das construções sociais em que a própria ideia de gênero se origina. Assim, é possível compreender que o espaço urbano reproduz formas de dominação que tendem a negligenciar mulheres, já que a estrutura e organização das cidades são elaboradas por uma classe dominante composta majoritariamente por homens brancos.

Desta forma, depreende-se que as mulheres ocupam espaços marginalizados na elaboração de políticas públicas e nas formas de ocupação urbana, fato que se torna ainda mais grave se considerarmos recortes interseccionais, como raça e, ainda, os recortes geracionais, destacando-se, neste ponto, a participação de mulheres jovens nos movimentos sociais nas cidades. Neste sentido, compreendemos que "num dado momento podem coexistir discursos concorrentes sobre uma mesma cidade, podendo fatores de ordem diversa contribuir para que um discurso torne-se dominante e para que os outros sejam silenciados" (MIRANDA, 2014, p. 164).

Logo, se o espaço urbano reproduz relações de gênero que produzem uma dominação masculina, é possível afirmar que o discurso dominante nas cidades decorrente dessa mesma dominação, tem silenciado pautas feministas nas cidades. 
Deste modo, se essas relações de gênero são utilizadas como formas de silenciar as mulheres e suas reivindicações, nada mais natural que o movimento de luta pelo espaço urbano também seja protagonizado por este grupo social, pois

quando se constata que as cidades se tornaram o que são com as formas de planejamento e gestão urbanas pensados e executados majoritariamente por homens, é de se esperar que a revolução urbana seja feminista e interseccional (anti-racista, antihomofóbica e não-sociocêntrica), para que, de fato, outros modos de pensar e agir possam ser considerados uma renovação da vida urbana (OLIVEIRA, 2018, p. 130)

Assim, evidenciam-se dois pontos essenciais para que a luta feminista seja de fato englobada no direito à cidade: que as formas de planejamento e gestão urbanas sejam executadas e pensadas por mulheres e que seja decorrente de uma abordagem feminista interseccional.

Primeiramente, sobre o planejamento e gestão urbana, vemos que as pautas tradicionais de políticas públicas destinadas às mulheres limitam-se a questões que acabam reproduzindo formas de dominação masculina e, por isso, não são eficazes no cotidiano das mulheres que vivem nas cidades. A título de exemplo, é comum que a construção de creches seja relacionada com as necessidades das mulheres trabalhadoras nas cidades, porém a localidade destes serviços não se harmoniza com as rotas de transporte público. Deste modo, elas cotidianamente gastam mais tempo que os homens para se deslocarem no espaço urbano, já que antes de ir para o trabalho precisam exercer as funções de cuidado no ambiente doméstico e deixar as/ os filhas/os em uma creche (que normalmente está situada em um bairro diverso da sua residência) para só então deslocar-se para o trabalho.

Este fato denuncia que as políticas públicas elaboradas por homens não contemplam particularidades essenciais à vida das mulheres - e nem poderia, já que eles não enfrentam as mesmas limitações no espaço urbano, pois, conforme já dito, este espaço foi pensado e construído por (e para) homens. A autora Diana Helene foi clara ao trabalhar este ponto em seu estudo denominado "Gênero e direito à cidade a partir da luta dos movimentos de moradia”, ao dizer que

A mobilidade não é pensada para trajetos pequenos e polarizados no entorno dos bairros habitacionais, mas, sobretudo, para os trajetos longos/pendulares entre residência e trabalho. Podemos observar tal fato de forma clara na estrutura viária típica de nossas cidades, radial, que liga centro e periferia, mas que não conecta entre si os bairros não centrais, sendo necessário, muitas vezes, um transporte até a área central para se locomover a um bairro vizinho, no qual se localizaria a escola das crianças, o mercado ou o posto de saúde mais próximo. (HELENE, 2019, p. 960) 
Como a divisão sexual do trabalho historicamente impôs às mulheres os deveres de cuidado com as/os filhas/os, as/os mais velhas/os e o ambiente doméstico, os homens sequer conhecem as necessidades cotidianas ligadas às atividades reprodutivas (HELENE, 2019). Assim, por não sofrerem com as limitações decorrentes destas atividades, os homens circulam mais fácil e rapidamente pelo espaço urbano, o que facilita seu acesso a universidades, melhores empregos, locais de lazer, e, consequentemente, gera um maior sentimento de "pertença" nas cidades, enquanto as mulheres estão mais isoladas e restritas aos espaços domésticos, o que acentua ainda mais a divisão sexual do trabalho nas cidades.

Esse sentimento de pertença refere-se à ocupação do espaço urbano como um local prático, no qual os sujeitos possam desempenhar suas identidades de gênero (MIRANDA, 2014). Assim, podemos dizer que se o sujeito não possui sentimento de pertença em relação a um determinado lugar, a sua presença neste é vista como não permitida. Porém, se o espaço não é permitido ao sujeito, é evidente que este não usufrui plenamente do direito à cidade. A partir do trabalho Fenster (1998), Joana Miranda diz que

a cidade revela-se um espaço simultaneamente libertador e ameaçador. A mobilidade espacial das mulheres continua condicionada pelas significações culturais simbólicas do espaço, pelos espaços de pertença e de não-pertença, permitidos ou não permitidos. Nestas condições, o 'direito à cidade' que Lefebvre se refere, direito ao uso de espaços públicos, acaba por não encontrar uma concretização. (MIRANDA, 2014, p. 166)

De igual forma, "o direito de mudar a nós mesmos pela mudança da cidade", defendido por David Harvey (2012, p. 74) e apontado no início deste artigo, também não irá se concretizar se o espaço urbano reproduzir formas de dominação machistas, sexistas, racistas, homofóbicas, transfóbicas, etc. Como veremos nas próximas seções, estas mudanças ocorrem, dentre outros meios, pelos movimentos sociais no contexto urbano.

Além disso, o sentimento de pertença e a performatividade se relacionam a fatores de gênero ligados à identidade do sujeito e também ao seu corpo. Importante destacar que a performatividade refere-se à replicação e à repetição de certos desempenhos que estão associados com práticas ritualistas (MIRANDA, 2014). Essas práticas são comportamentos cotidianos que dão vida aos espaços urbanos pela forma como os indivíduos se mostram e se relacionam com questões de gênero, de comportamento e culturais, as quais vão se referir também aos próprios corpos dos sujeitos neste ambiente. Partindo deste ponto, é possível dizer que homens e mulheres apresentam diferentes pertenças a depender do espaço urbano em que circulam. Por exemplo: em muitas cidades do mundo, as ruas durante a noite não são um local permitido às mulheres, pois estão mais sujeitas a serem expostas a crimes sexuais; no entanto, este perigo é menor ou inexistente para os homens, 
que se defrontam com outros tipos de violência. Ou seja, os corpos femininos estão suscetíveis a riscos e violências no espaço urbano de natureza diversa daquelas a que estão sujeitos os corpos masculinos. E isso define muito o que cada um pode fazer nesse espaço, constituído à maneira de um território. Como trabalhado por Joseli Maria Silva no artigo intitulado "Gênero e Sexualidade no Espaço Urbano":

os espaços de constrangimento, como a rua em determinados locais e horários, ou espaços de confinamento, como as residências em periferias distantes, são claramente elementos que tanto se referem às diferenças de acesso físico entre mulheres e homens a determinados espaços, como a construção de barreiras invisíveis criadas pelo olhar e força daqueles que impõe sua ordem e alcançam legitimidade (SILVA, 2007, p. 120)

Em seu estudo sobre mulheres e a experiência da solidão, AUTORA (2019) descreve o desejo de liberdade de ir e vir expresso por mulheres jovens e a sensação de medo provocada por esta experiência de estar só. Uma mulher, em geral educada para servir ao outro, encontra resistência e julgamento se quer insistir em sua liberdade. Simone de Beauvoir já enunciava esta contradição em suas reflexões biográficas (DE BEAUVOIR, 2010) e em O Segundo Sexo (1985). As questões que tangenciam gênero e geração são apresentadas adiante.

Assim, evidenciamos, mais uma vez, que a negligência às pautas feministas e de gênero no contexto urbano é uma consequência da predominância dos interesses da classe dominante, notadamente composta por homens brancos. É por este motivo que a produção da cidade deve se ater às pautas feministas, pois

É preciso considerar que a vivência urbana é radicalmente diferente para homens e mulheres e muito mais difícil para as mulheres negras, trans e/ou habitantes das periferias, que são as que mais frequentemente sofrem os impactos deste padrão de urbanização excludente e patriarcal (OLIVEIRA, 2018, p. 125)

Este ponto se relaciona diretamente ao segundo fator aqui apontado como essencial para que as pautas das mulheres sejam de fato englobadas no direito à cidade: que seja decorrente de lutas feministas de caráter interseccional. A necessidade de inserir questões geracionais, de raça, de classe e de sexualidade é essencial no contexto urbano, não só por permitir a elaboração de políticas públicas específicas para os grupos sociais destes eixos, mas por evidenciar que se mulheres enfrentam dificuldades e riscos no uso do espaço urbano, essa dificuldade é ainda maior se referirmos as mulheres negras e, ainda mais, se referirmos as mulheres trans.

Neste sentido, destacamos as formas como as intervenções pela luta do espaço urbano ocorrem e como reclamam o direito à cidade numa perspectiva interseccional. Na cidade do Rio de Janeiro, por exemplo, o projeto Feminicidade 
articulou dezenas de voluntárias com o objetivo de registrar histórias de mulheres por meio de fotografias, frases e poesias e estampá-las em cartazes pela capital carioca, como uma forma de promover e disseminar debates sobre o movimento feminista e também sobre empoderamento feminino (OLIVEIRA, 2018). Ao falar sobre este projeto também não poderíamos deixar de destacar a frase de Marielle Franco, pois se relaciona diretamente à abordagem interseccional defendida neste estudo, de que a revolução "tem que ser feminista e tem que ser negra”, a qual também relacionamos à fala de Angela Davis, já destacada dentro do movimento feminista e antirracista, de que não basta não ser racista, é necessário ser antirracista (DAVIS, 2016). Trazendo este ponto para a análise do direito à cidade, não basta que a prática de produção do espaço urbano contemple a luta de mulheres brancas que ocupam lugares privilegiados, também deve ser

Uma luta de mulheres que pensam o direito à favela, como direito à cidade; que lutam contra o racismo em um país que entre os anos de 2002 e 2013 , teve um aumento de assassinatos de mulheres negras ampliado e mais de $54 \%$; de mulheres que lutam contra o lesbocídio (assassinato de lésbicas), contra a transfobia e a homofobia, contra a intolerância religiosa, contra o racismo institucionalizado em sistemas jurídicos e naturalizado no cotidiano e contra as violações sofridas pelas mães dos jovens negros assassinados. (OLIVEIRA, 2018, p. 133)

Somente a partir destas análises e considerando as vivências e necessidades cotidianas destes grupos é que será possível falar em um amplo direito à cidade. Logo, é evidente que a luta por este direito (ou seja: pelo uso e pertença ao espaço urbano) deve englobar questões pensadas e planejadas por (e para) mulheres, com o intuito de erradicar as reproduções da dominação masculina no espaço urbano. Como dito anteriormente, uma das formas de reivindicar o direito à cidade é por meio dos movimentos sociais, por isto na próxima seção abordaremos a luta pelo direito à cidade com foco no recorte geracional.

\section{As mulheres jovens na luta pela cidade: uso político do corpo e conflito de gerações}

A problemática da luta pela cidade a partir de uma perspectiva de gênero está em inúmeros atos públicos organizados pelos movimentos feministas no Brasil e no Mundo, como a Marcha das Vadias, a Marcha Anual das Mulheres e o protesto Un violador en tu camino. Movimentos como estes utilizam intervenções culturais, passeatas, ocupações e o corpo, como plataforma política, entre outras estratégias de contestação e subversão. No entanto, eles estão longe de representar uma homogeneidade do feminismo e são marcadas por inúmeras disputas e contradições 
entre diferentes identidades e práticas feministas, que emergem a partir de questões relacionadas à sexualidade, raça, geração, classe, entre outras. Nesta seção, partiremos do caso da Marcha das Vadias, tomando como ponto central a questão do corpo, para refletir sobre a complexidade desse movimento social. A partir desse exemplo colocaremos a importância da questão geracional dentro do feminismo, que é também uma categoria fundamental para compreender as lutas das mulheres jovens nas e pelas cidades.

Seguindo as definições e localizações históricas que se repetem em diversos trabalhos (JERER, 2014; GOMES e SORJ, 2014; BATISTA, 2018, entre outros), a Marcha das Vadias surgiu em Toronto, no Canadá, em 2011, em reação à declaração de um policial em um fórum universitário sobre violência no campus. Segundo ele, as mulheres poderiam evitar serem estupradas ao não se vestirem como sluts (vagabundas, putas, vadias). Sua fala evoca argumentos utilizados na cultura do estupro, que justifica a violência sexual com base no comportamento e no corpo das mulheres. Por isso, a primeira Slutwalk teve como principais bandeiras o fim da violência sexual e da culpabilização das vítimas, em vez dos agressores. O movimento foi amplamente divulgado na internet, o que levou a organização de outras marchas em diversas partes do mundo. No Brasil, a primeira Marcha das Vadias foi realizada em 2011, na cidade de São Paulo (GOMES e SORJ, 2014).

Inicialmente, a organização e o público desses protestos esteve identificado com mulheres brancas, jovens, universitárias e de classe média. No entanto, o movimento também contou com a participação de mulheres da comunidade LGBTQIA+, em especial lésbicas e transexuais, mulheres negras, homens identificados com o feminismo, mulheres mais velhas, entre outras. Essa pluralidade gerou uma série de perspectivas díspares sobre os atos públicos e suas intervenções políticas, que podem ser exemplificadas a partir da questão do corpo e da nudez nos protestos.

Nessas marchas o corpo tem um duplo papel: por um lado ele é reivindicado e por outro é utilizado como uma plataforma política. A reivindicação se dá pela luta das mulheres pela autonomia de seus corpos, enquanto o uso político do corpo subverte o termo vadia como uma estratégia de empoderamento. Por isso, as mulheres fizeram uso da nudez, de roupas curtas e maquiagens, elementos utilizados para atribuir a uma mulher o rótulo pejorativo de vadia numa cultura machista. Essa ideia central é ilustrada em um dos slogans do movimento, "Se ser livre é ser vadia, então somos todas vadias”. Essa posição segue o perfil inicial das organizadoras do movimento, mulheres brancas, jovens, universitárias e de classe média, e tem sido colocada em questão em cada contexto de realização das marchas (GOMES e SORJ, 2014).

Tal perspectiva não é hegemônica e é pensada de diferentes formas a partir de diferentes identidades mobilizadas nos movimentos feministas. Por exemplo, as mulheres negras questionam o uso da nudez tendo em vista o longo processo de hipersexualização do corpo negro na sociedade brasileira. Para elas, a sua luta constante tem sido demonstrar que não são vadias, lutando contra estereótipos sensualizados como o da mulata, da globeleza, e serem reconhecidas também como médicas, advogadas, escritoras, etc. As feministas mais velhas também colocam a 
questão em outros termos, para elas, a autonomia do corpo está vinculada a questões como a saúde da mulher, descriminalização do aborto e o planejamento familiar (GOMES e SORJ, 2014). Segundo Paula Batista (2018), o uso político do corpo tem sido uma questão que coloca em conflito gerações de militantes feministas. Sua investigação sobre a Marcha das Vadias em Goiânia mostra uma relutância das feministas "históricas" em relação à nudez em protestos. Para elas, tal exposição entra em choque com a formação subjetiva de sua geração, marcada por valores morais associados à preservação do corpo à esfera da intimidade, de forma que essa exibição está associada a formas de repressão baseadas em insultos como "puta" ou "vadia”. Por sua vez, as militantes jovens argumentam que o corpo fala e ressaltam sua importância enquanto estratégia subversiva.

Para nós, as diferenças geracionais tem um papel central no feminismo e nas lutas das mulheres jovens nas e pelas cidades e não apenas em relação ao corpo. Um estudo realizado pela Fundação Perseu Abramo mostra que as mulheres jovens são as que mais se consideram feministas, $40 \%$ das mulheres de 15 a 17 anos e $37 \%$ das de 25 a 34 anos se consideram feministas. Este grupo tem colocado novas formas de identificação, como "jovens feministas", por exemplo, formas de atuação política e novas questões para o movimento, como o "adultocentrismo", que revela relações de poder dentro do movimento de mulheres que conferem autoridade às mulheres mais velhas. Dessa forma, sua atuação se dá com conflito e colaboração, pois consideram importante aprender com as mais velhas ao mesmo tempo em que disputam espaços de poder e liderança (GOMES e SORJ, 2014).

O feminismo como movimento social global costuma ser periodizado em ondas e esta é uma narrativa sobejamente conhecida. Em suas expressões mais recentes, que podemos remeter à passagem ao século XXI, o fenômeno das "jovens feministas” é um divisor de águas (AUTORA, 2016; AUTORA; COAUTORA, 2013). Suas vozes, seus corpos e suas tecnologias discursivas e políticas são o contraponto necessário a uma geração que experimentou o sabor de muitas conquistas e que se encontrava em crise. Nos anos 2000, muitos deslocamentos acontecem no feminismo brasileiro: as organizações não governamentais (ONGs) perdem força, decorrente, sobretudo, da queda dos apoios financeiros internacionais; há uma migração considerável de massa crítica para a academia e para o Estado e uma ausência de lideranças nos chamados movimentos de base, sindicatos e partidos. Esta geração, que havia (re)articulado o feminismo na redemocratização dos anos 1980, embora tendo investido pesadamente em formação política, encontra-se sem renovação. Ao cabo de 30 anos, o movimento está carente de processos de transmissão (AUTORA, 2016; AUTORA; CO-AUTORA, 2011). Emergem com vigor, nesse período, reivindicações de um feminismo radicalmente autônomo, desvinculado das feições formais e organizativas que marcaram os anos 1980 e 90. São formas criativas e dispersas - ou sidestream, para usar a expressão de Sônia Alvarez (2014) - que interpelam o lugar estabelecido do feminismo anterior. Há uma crítica à centralização de poder, à baixa incidência de temas da juventude e seus protagonismos e, por fim, a reivindicação de que as jovens sejam vistas e tratadas como sujeitos do feminismo. 
Esta é uma crise que atravessa todas as expressões feministas desse período. Flávia Rios e Regimeire Maciel (2018) discutem essas mesmas premissas para o feminismo negro, reconhecendo-lhe as clivagens geracionais. As marchas, enquanto recurso comunicacional, político, pedagógico e artístico, são performances que tomam as ruas do país em suas diferentes composições: marcha mundial de mulheres, marcha das mulheres negras, marcha das margaridas, marcha das vadias, marcha internacional de mulheres, etc. Tais movimentos, às vezes circunscritos à organização das marchas em si, são de muitos matizes, mas alguns deles utilizam elementos comuns: o corpo nu ou seminu como plataforma de protesto, a ressignificação de termos e expressões pejorativas como "vadia" e o ocorrerem em centros urbanos, no âmago das cidades.

Essas perspectivas distintas apontam para diferentes formas de luta nas e pelas cidades marcadas pela geração e também por outros marcadores sociais de diferença, o que nos leva à pergunta de como se dá a atuação política das mulheres jovens nas cidades. Neste artigo não temos a pretensão de esgotar essa questão, mas iremos utilizá-la como um caminho para analisar uma das formas de luta protagonizada por elas na sociedade brasileira, os movimentos de ocupação secundaristas de 2015 e 2016.

Este movimento e o feminismo tem certa aproximação, mesmo que ele não tenha surgido como uma articulação propriamente feminista, suas principais personagens foram mulheres jovens, em sua maioria, de 15 a 17 anos. Essa característica ficou evidente em um de seus principais lemas: "lute como uma menina". Como veremos na próxima seção, a capilaridade do movimento feminista se fez presente no dia a dia das ocupações e esteve presente na prática das estudantes como forma de contestação às relações de gênero normalizadas socialmente. Deste modo, a partir da compreensão de que há uma forte presença de mulheres jovens em movimentos sociais pelo direito à cidade, na próxima seção aprofundaremos na análise de ocupações secundaristas, com o objetivo de elucidar de que forma o protagonismo das jovens foi observado e vivenciado por elas mesmas dentro da organização destes movimentos.

\section{As ocupações secundaristas de 2015 e 2016 e o protagonismo das mulheres jovens}

No Brasil, as mulheres têm feito uso das ocupações como estratégias para fazer reivindicações ao Estado. Amanda Cegatti (2018), nos fornece alguns exemplos ao analisar as ocupações do Movimento Olga Benário nas cidades de Belo Horizonte, Porto Alegre e Mauá, em 2016. Segundo ela, a apropriação de espaços públicos como o bandejão da Universidade Federal de Minas Gerais e prédios inabitados no Rio Grande do Sul e em São Paulo, foram formas de dar visibilidade à suas demandas pela responsabilização do Estado diante das situações de violência contra a mulher. Através delas o movimento pressionou o governo e conquistou a criação de centros 
de referência para o acolhimento de mulheres em situação de violência. Outro exemplo aconteceu na universidade em que estamos, em 2015, um suposto caso de estupro, no Campus II da Universidade Federal de Goiás (UFG), mobilizou as estudantes para a ocupação da reitoria, com uma série de reivindicações, dentre elas, melhores condições de segurança nos campi e ampliação das disciplinas sobre questões de gênero e sexualidade. Deste modo, compreendemos o movimento de ocupações secundaristas de 2015 e 2016 na intersecção entre esses dois contextos: por um lado ele surge como uma forma de fazer demandas ao Estado (principalmente por uma educação pública, gratuita e de qualidade, além das reivindicações por maior segurança e visibilidade de questões de gênero) e, por outro, é marcado pelo protagonismo das mulheres jovens. Dessa forma, analisar as estratégias de luta dessas ocupações nos fornece uma perspectiva parcial sobre as formas de atuação política dessas mulheres nas cidades, sem esgotar seu campo e formas de atuação, uma vez que elas também participam de outros movimentos, como os mencionados na seção anterior.

Nos anos de 2015 e 2016 uma profusão de medidas autoritárias e projetos de lei retrógrados sobre a educação pública brasileira, incitaram uma série de debates, reflexões e mobilizações sociais. Alguns deles foram o projeto de reorganização das escolas públicas do estado de São Pauloª, a tentativa de implementação de Organizações Sociais (OSs) ${ }^{2}$ nas escolas públicas de Goiás, a Proposta de Emenda Constitucional 55 (PEC 55)3 , a Reforma do Ensino Médio (Medida Provisória 744) ${ }^{4}$, e o movimento de militarização das escolas públicas ${ }^{5}$. Dentre as inúmeras formas de resistência a tais medidas destacam-se o movimento de ocupações secundaristas desses anos, que começaram em São Paulo, mas tiveram forte atuação nos estados de Goiás, Rio de Janeiro, Paraná, Rio Grande do Sul e Ceará.

Entendemos essas mobilizações como um movimento social urbano, caracterizado, principalmente, pela luta por uma educação pública, gratuita e de qualidade, mas atravessado por outras questões como a recuperação e apropriação de

1 Plano de reorganização das escolas de ensino fundamental e médio do estado de São Paulo que previa o fechamento de 92 escolas e a mudança para ciclo único de mais de 700 escolas.

2 OSs são entidades sem fins lucrativos, que recebem recursos do estado para administrar algum órgão público.

3 A PEC 55, mais tarde sancionada como a Emenda Constitucional no 095, alterou a constituição brasileira com a implementação do Novo Regime Fiscal. Essa medida limitou os gastos e investimentos públicos aos mesmos valores do ano de 2016 corrigidos pela inflação.

4 Com o objetivo de modernizar a formação média no Brasil, o governo federal implementou um conjunto de ações para a educação nacional via medida provisória (MP 746/16) sem debate algum com a sociedade. Entre outras medidas, ela inclui a adoção de um currículo formado por itinerários comuns e específicos escolhidos pelos/as estudantes e a retirada do ensino de espanhol num país da América Latina. Após muitas críticas alguns pontos foram revistos, como a exclusão das disciplinas Artes, Educação Física, Filosofia e Sociologia da Base Nacional Comum Curricular (BCNN) (GOMES, 2018).

5 Crescente processo de entrega da gestão das escolas públicas à Polícia Militar ou a militares em processo em vários estados do país. Lançado em setembro de 2019, o Programa Nacional de Escolas Cívico-Militares promete intensificar esse caminho com a militarização de mais 216 escolas. Tais projetos são concebidos sob uma perspectiva da educação moral e cívica e do patriotismo. 
espaços públicos e o feminismo, por exemplo. Dentro dessa perspectiva, as ocupações de escolas funcionaram como uma estratégia para fazer demandas ao Estado, principal interlocutor desse movimento, assim como forneceram uma experiência crítica das cidades baseada em grande medida numa perspectiva geracional e de gênero, uma vez que o principal sujeito político dessas mobilizações foram as mulheres jovens. Por isso, a atitude política desse movimento se dá no sentido de fazer algo presente ou de dar expressão a algo, evidenciando pautas relacionadas à educação, mas que não se limitam a ela, como o autoritarismo, o sexismo, o racismo, o direito às cidades, entre outras.

Nesta seção fazemos uma análise a partir de três entrevistas realizadas com estudantes que participaram dessa mobilização no estado de Goiás, mais especificamente na capital, Goiânia. A partir das falas das alunas pudemos pensar as principais características do movimento, as redes estabelecidas entre as estudantes e a cidade e a dimensão pedagógica dos movimentos sociais. Participaram deste estudo Ana Júlia, autodeclarada branca, na época com 17 anos e estudante do Centro de Pesquisa e Ensino Aplicado à Educação (CEPAE), na região norte de Goiânia, Regiane, autodeclarada negra, na época com 16 anos e estudante do Colégio Estadual Ismael Silva de Jesus, na região noroeste e Ana Beatriz, autodeclarada negra, na época com 18 anos, tendo estudado no Colégio Lyceu de Goiânia, na região central.

Pensando na geografia da cidade, esses colégios desempenharam papéis diferentes no movimento devido a suas características específicas, que não podem ser consideradas apenas pela sua localização espacial. No caso de Goiânia, as ocupações podem ser divididas em duas ondas, uma em 2015 e outra em 2016, que se opunham a questões distintas, a implementação das OSs e a PEC 55, a MP 744 e o Projeto Escola sem Partido, respectivamente. Nesse cenário, o Lyceu foi um dos primeiros a ser ocupado devido a sua localização central e a proximidade com um dos principais pontos para atos públicos da cidade, a praça cívica, onde foram realizadas manifestações de professoras/es e estudantes. A partir da região central as ocupações se espalharam para escolas periféricas, como o Ismael. Por sua vez, o CEPAE só foi ocupado em 2016 devido ao fato de ser uma escola federal ligada à Universidade Federal de Goiás (UFG) e, portanto, não estava incluída no projeto das OSs, já que era gerida por outra instância de poder. Essa característica também o diferencia das demais escolas, pois apesar de sua localização periférica ela é mais elitizada, tanto pela estrutura mais próxima da academia, quanto pelo público que a frequenta.

A distribuição das ocupações por toda a cidade estabeleceu uma importante rede de sociabilidade. As estudantes relataram a participação em várias escolas, sendo que as três estiveram em escolas da região central antes de iniciarem o movimento nas instituições onde estudavam. Segundo elas, dessa troca de experiências surgiu uma rede de contatos fundamental para o sucesso do movimento, pois permitiu que estudantes que estivessem em situação desfavorável ou que não soubessem como ocupar suas escolas o fizessem. Além disso, ela permitiu o remanejamento e a redistribuição de recursos e pessoas entre ocupações mais ou menos abastecidas. Essa 
rede funcionou, principalmente, através de redes sociais, onde elas se comunicavam e divulgavam as atividades diárias do movimento e sua posição política.

A experiência dessas estudantes mostra que o movimento de ocupações foi fortemente caracterizado pela presença feminina, mas ainda assim o protagonismo das mulheres precisou ser construído constantemente. Isso ficou evidente nos relatos sobre o primeiro dia de ocupação, caracterizado por um ambiente de tensão, pressão psicológica, insultos e até ameaças à integridade física das ocupantes. Em alguns episódios, geralmente protagonizados por homens, pais de estudantes, o gênero foi mobilizado como agressão através de ofensas geralmente utilizadas contra mulheres, "vagabundas", "putas" e, em casos extremos, ameaças como "se entrarmos aí de noite vamos estuprar todo mundo". Além disso, se não fosse pelo posicionamento crítico das meninas, os papéis de gênero teriam sido reforçados nas primeiras assembléias, onde se negociavam regras e comissões para as ocupações, pois alguns participantes sugeriram que as mulheres deveriam ficar nas comissões de limpeza ou cozinha, por exemplo. No entanto, elas questionaram essa posição, redefinindo as relações de gênero do dia a dia das escolas.

Regiane: Você vê essa divisão na escola normal né, de gênero, saca? Estereótipo de gênero, na ocupação não, sabe? Você via menino lavando louça, menina na comissão de segurança, eu mesma até hoje nos atos faço parte da comissão de segurança, sabe? É isso mesmo, sabe? Das pessoas serem livres pra serem o que elas querem pra seguir o que elas querem ser, coisa que você

Essa subversão dos papéis sociais atribuídos ao gênero também aponta para um processo de subjetivação e construção de identidades baseados na crítica feminista e uma dimensão formativa dos movimentos sociais. Essas características adquirem uma importância especial se considerarmos a centralidade da questão geracional nas ocupações, pois a maioria das participantes eram adolescentes e viviam um período da vida marcado pelo desenvolvimento de uma perspectiva subjetiva sobre si e o mundo, bem como a formulação de projetos para o futuro, como a escolha de uma carreira para se dedicar após a conclusão do ensino médio, muitas vezes associada a escolha de um curso de graduação.

Regiane: [...] Mas com a ocupação sabe eu vi que eu não sou o que as outras pessoas falam, tipo ah tão lá só fazendo sexo, usando drogas e não era aquilo sabe? É, então eu comecei a pensar não 
cara, não é porque alguém diz algo sobre mim que eu sou aquilo sabe, e me ajudou com a depressão, sabe? [...] E na questão do feminismo, sabe? Que eu não nasci pra ter que me submeter a ninguém sabe, nem em questão de machismo, nem de família, querendo impor qualquer coisa que eu sou o que eu sou sabe e não o que outras pessoas acham que eu sou ou que elas querem que eu seja, sabe? Então isso foi muito importante sabe? Eu me tornei muito mais forte com a ocupação.

Ana Beatriz: Olha a importância da ocupação para a minha formação como pessoa e acadêmica é, assim, a partir da ocupação foi uma nova vida, eu renasci uma outra pessoa. Foi como se eu tivesse retirado uma casca que eu tinha e eu renasci de novo. Então assim, eu nunca vou esquecer desse momento da ocupação, que mudou totalmente a minha vida e não só a minha, eu tenho certeza, e a de todas as pessoas que passaram pela ocupação. Porque antes de eu entrar na ocupação eu tinha uma mente formada, formada não, eu tinha uma mente que eu dizia assim formada, mas que eu não tinha a mínima ideia do que eu tava fazendo. E após a ocupação eu decidi o que eu ia fazer como pessoa, o que eu ia estudar, hoje eu faço geografia licenciatura, eu tento ser professora. E se não fosse pela ocupação eu nunca teria escolhido esse curso, muito menos essa formação e talvez eu não seria a pessoa que eu sou hoje e não seria tão feliz quanto eu sou. Por ter passado por essa experiência, por ter conhecido essas pessoas e ter aprendido tudo que eu aprendi durante a ocupação, porque a ocupação não é somente a ocupação que a gente passa por ali e pronto. Eu vou levar isso para o resto da minha vida, todas as coisas que eu aprendi lá dentro, com aquelas pessoas, aquelas práticas, aquele tipo de organização autogestionário, que foi a que a gente praticou dentro da ocupação e que eu tento praticar na minha vida hoje é o meu ensinamento como vida, porque como eu praticava dentro da ocupação eu tento praticar hoje em dia, e isso dá certo. Eu vejo que dá certo. Dá muito mais certo que os outros tipos de práticas que a gente tem, então é assim, a importância total da minha vida. Se não fosse por isso eu não viveria dessa maneira.

Regiane: [...] eu penso muito em ser professora de história, sabe? Então eu penso muito no role da revolução na forma de educar, de formar o pensamento crítico entre os alunos, começando do prezinho sabe, da creche, do CMEI.

Essa dimensão formativa está ligada tanto a autonomia envolvida no processo de luta e articulação política, quanto ao currículo alternativo construído nas escolas ocupadas. Durante o movimento as/os estudantes construíram uma programação de atividades diárias, que era composta por oficinas e atividades culturais oferecidas por 
pessoas da sociedade civil ou pelas/os próprias/os ocupantes. Essas ações abordaram diversos temas como defesa pessoal, participação política, racismo, sexualidade, feminismo, entre outras. As estudantes relataram já ter alguma experiência relacionada ao feminismo através de redes sociais, processo que se intensificou com as ocupações onde essas discussões estiveram bastante presentes. As oficinas permitiram uma melhor distribuição desses debates pela cidade, além de colocar a importância dos saberes localizados das periferias ao levá-los para os espaços educacionais, onde não encontravam espaço no currículo regular.

Esse currículo alternativo também estava envolvido pela autonomia das/ os estudantes em elaborar e executar suas próprias atividades e solucionar os conflitos que surgiam no seu dia a dia sem a intervenção das/os adultas/os. Todos esses elementos fazem parte de uma dimensão formativa da luta pela educação e, consequentemente, pelas cidades, reforçando a afirmação já citada de David Harvey, as ocupações secundaristas proporcionam o direito de mudar a si mesma/o através da luta pela cidade:

Ana Júlia: [...] tinha gente que não sabia fazer um arroz, aprendeu. Não sabia lavar um banheiro, aprendeu. Então a gente teve essa vivência de aprender a fazer coisas que a gente não sabia, a gente teve um espaço aberto de diferentes opiniões de diferentes assuntos, todo mundo podia falar hora que quisesse, debater, a gente teve a chance de tomar decisões por nós mesmos, coisas que a gente nunca tinha feito na escola. Então assim, foi uma oportunidade de amadurecimento mesmo porque quando tá tendo aula a gente tem um problema, leva pra coordenação, na ocupação a gente tem um problema senta aqui e resolve.

Dessa forma, as ocupações secundaristas também revelam um caráter de conflito geracional envolvido na educação das/dos estudantes, pois o processo de formação da escola regular está centralizado na figura do/da professor/a, onde uma pessoa mais velha transmite saberes de forma autoritária para as/os estudantes. Como vimos, essa é uma temática que as jovens feministas também colocam dentro deste movimento, no entanto, na educação essa relação se dá de forma mais autoritária ainda, pois as/os alunas/os, poucas vezes, tem condições de contestar ou disputar espaços de poder com as/os educadoras/es.

Ana Beatriz: A principal diferença da escola do dia a dia pra das ocupações é que ela é patriarcal e totalmente autoritária. Em que você vive em um ambiente, que você ta ali pra aprender com pessoas iguais a você, com idades diferentes, mas todos somos iguais, iguais assim, dependendo do ponto de vista. Mas em que a gente é obrigado a aceitar certo tipo de regras que a gente não concorda, mas que pessoas mais velhas que a gente, que estão numa posição mais forte que a gente, concordam. E durante 
a ocupação a diferença é que a gente entra em um consenso, que todos aceitam as práticas que devem ser feitas, então há divergência de ideias, porém a maioria entra em consenso pra que isso dê certo e não é simplesmente jogado de cima para baixo. A gente conversa e assim que entra em consenso a gente faz as coisas pra ninguém ficar contra, é um acerto de ideias. E o que eu acho muito melhor que a escola do dia a dia, porque a do dia a dia não dá certo, em que uma ordem é mandada de cima para baixo e as pessoas tem que aceitar, mas as pessoas não aceitam na verdade, e que dia que isso dá certo?

Regiane: Eu acho completamente errada a forma como eles expõem o conteúdo e a forma como eles avaliam, [...]. Mas assim, sei lá, tipo eu acho que seria muito mais válido por exemplo sei lá, trabalho de história, eu estudar aquele assunto e sei lá eu dou um seminário sabe? Eu falo sobre aquilo, porque pra saber falar sobre aquilo eu tenho que entender aquilo eu tenho que entender todo o contexto, eu tenho que entender o que está ali, sabe? É muito engraçado, se eu falo alguma coisa, se eu levanto a mão e discordo, se eu tenho um argumento melhor que o dele ele me manda pra fora da sala. É muito estranho isso sabe? Eu estou sobre você, eu sou a autoridade sobre você, abaixe a cabeça, me escuta e cala a boca. E quem não faz isso leva advertência, suspensão, você é expulso da escola.

As ocupações secundaristas de 2015 e 2016 foram movimentos sociais de caráter notoriamente feminino, protagonizado por estudantes de 15 a 17 anos, em várias cidades brasileiras. Esse movimento apresenta relações com o movimento feminista a partir da capilaridade que as questões de gênero alcançam na sociedade brasileira. A partir de experiências prévias com a militância feminista na internet as estudantes desenvolveram práticas críticas às relações de gênero, que contestavam o papel socialmente atribuído às mulheres, o autoritarismo, questões geracionais e as relações de poder presentes nos espaços escolares. Além disso, a mobilização social funcionou como um processo de formação, que desencadeou processos de subjetivação ativos na constituição de suas próprias identidades e na construção de projetos futuros a partir da luta urbana pela educação.

\section{Considerações Finais}

Defendemos, com este trabalho, o posicionamento de que o direito à cidade deve ser pensando de forma integrada a uma pauta feminista interseccional e também considerando o fator geracional, já que mulheres jovens ocupam espaços de destaque nos movimentos sociais que reivindicam o sentimento de pertença às cidades. Se a vida do espaço urbano é construída pela performatividade dos sujeitos, este espaço 
deve integrar as várias formas de ocupá-lo e não apenas se limitar aos interesses dos grupos hegemônicos que integram o espaço de decisão e de formulação de políticas públicas. Assim, acreditamos que somente uma cidade pensada e elaborada para contemplar variados grupos sociais pode gerar nestes o sentimento de pertença e permitir com que pratiquem livremente sua performatividade.

Dentre esses grupos sociais, destacamos as mulheres jovens, as quais vêm ocupando papéis de destaque em movimentos sociais que reclamam o direito à cidade, principalmente no feminismo. Seja reivindicando seus próprios corpos ou utilizandoos como uma plataforma política por meio da nudez, as jovens chamam atenção ao fator geracional dentro do próprio movimento feminista, reivindicando sua posição enquanto sujeito integrador desta luta. Neste ponto, destacamos a presença das jovens na Marcha das Vadias e a elevada porcentagem com que estas se autodenominam feministas, um fator ainda não percebido em outros grupos geracionais. Essa análise também nos leva ao protagonismo destas jovens nos movimentos de ocupações secundaristas, os quais não se afastam das pautas feministas, tampouco da luta pelo direito à cidade.

A partir da investigação sobre os movimentos secundaristas percebemos que, apesar da forte presença de jovens feministas, o seu protagonismo teve que ser construído e reforçado de uma maneira constante. Tal fato foi percebido, dentre outros fatores, pelos relatos das jovens, nos quais denunciam que papéis de gênero seriam reforçados se não fosse seu posicionamento crítico, chegando até mesmo a ameaças de agressões de crimes sexuais. Isso revela o caráter permanente e constante da luta dessas jovens feministas, já que além de reivindicarem seu direito a um ensino de qualidade, ao acesso pleno à cidade e aos seus próprios corpos, elas também precisam se posicionar e lutar por sua autonomia dentro do movimento.

As estratégias de luta e atos públicos baseados na ocupação de espaços urbanos foram uma plataforma para ressignificar e construir identidades baseadas no gênero. Assim, o protagonismo das jovens feministas nos movimentos secundaristas reflete a sua luta pelo direito à cidade, o qual contempla a inclusão de pautas interseccionais como ponto essencial para o sentimento de pertença e de livre acesso e utilização do espaço urbano.

\section{Referências}

AUTORA. Nome da obra, 2019 [informação a ser completada após avaliação ad hoc]

AUTORA; CO-AUTORAS (2013) [informação a ser completada após avaliação ad hoc] AUTORA; CO-AUTORA (2011) [informação a ser completada após avaliação ad hoc] 
BATISTA, Paula Nogueira Pires. "É uma questão de geração, eu não uso meu corpo assim”: Diferenças geracionais e diferentes feminismos a partir da Marcha das Vadias de Goiânia/GO. Teoria e Cultura, v. 13, n. 1, 2018.

DAVIS, Angela. Mulheres, raça e classe. Tradução: Heci Regina Candiani. São Paulo: Boitempo, 2016.

DE BEAUVOIR, Simone. O Segundo Sexo. Rio de Janeiro: Nova Fronteira, 1985.

DE BEAUVOIR, Simone. A força da idade. Rio de Janeiro: Nova Fronteira, 2010.

FENSTER, Tovi. Ethnicity, citizenship and gender: the case of Ethiopian immigrant women is Israel. Gender, Place and Culture. Abingdon. v. 5, n. 2, 1998, p. 177-189.

GOMES, Carla; SORJ, Bila. Corpo, geração e identidade: a Marcha das vadias no Brasil. Soc. estado. Brasília, v. 29, n. 2, p. 433-447, ago. 2014. Disponível em: http:// www.scielo.br/scielo.php?script=sci_arttext\&pid=S0102-69922014000200007\&lng=p t\&nrm=iso. Acesso em: 03 out. 2020.

GOMES, Nilma Lino. O movimento negro educador. Saberes construídos na luta por emancipação. Petrópolis, Rio de Janeiro: Vozes, 2017.

HARVEY, David. O direito à cidade. In: Lutas Sociais, n. 29. São Paulo: PUCSP, 2012, pp. 73-89.

HELENE, Diana. Mulheres e direito à cidade a partir da luta dos movimentos de moradia. In: V ENANPARQ. Salvador, FAUFBA, 2019.

LEFEBVRE, Henri. O direito à cidade. São Paulo: Centauro, 2001.

MIRANDA, Joana. Numa urbe genderizada: vivência dos espaços. Revista Latinoamericana de Geografia e Gênero, Ponta Grossa, v. 5, n. 2, ago. / dez. 2014, p. 163-174.

OLIVEIRA, Anita Loureiro de. Mulheres e ação política: lutas feministas pelo direito à cidade. Revista PerCursos, Florianópolis, v. 19, n. 40, maio/ago. 2018, p. 111-140.

REJER, Jo. The Story of a Slut Walk: Sexuality, Race, and Generational Divisions in Contemporary Feminist Activism. Journal of contemporary ethnography, 2014. Disponível em: https://journals.sagepub.com/doi/ abs/10.1177/o891241614526434?journalCode=jcec Acesso em setembro de 2020.

RIOS, Flávia M.; MACIEL, Regimeire. Feminismo negro brasileiro em três tempos: mulheres negras, negras jovens feministas e feministas interseccionais. Labrys, 
études féministes/ estudos feministas julho/ 2017- junho 2018 /juillet 2017-juin 2018. Disponível em: https://www.labrys.net.br/labrys31/black/flavia.htm. Acesso em setembro de 2020 .

SILVA, Joseli Maria. Gênero e sexualidade na análise do espaço urbano. Revista Geosul, Florianópolis, v. 22, n. 44, jul./dez. 2007, p 117-134.

Recebido em 30/10/2020.

Aceito em 23/11/2020. 